\title{
Layered Grouting Technology Based on a Comprehensive Water-to-Cement Ratio for the Overlying Loess Stratum of Urban Shallow Tunnels
}

\author{
Teng Yang, Jiaqi Zhang, Xiao Zhang $(\mathbb{D}$, Qingsong Zhang, and Zhanchao Yin \\ Geotechnical \& Structural Engineering Research Center, Shandong University, Jinan 250061, China \\ Correspondence should be addressed to Xiao Zhang; sduzhangxiao@sdu.edu.cn
}

Received 2 January 2020; Revised 25 May 2020; Accepted 2 June 2020; Published 16 June 2020

Academic Editor: Chun-Shun Zhang

Copyright (c) 2020 Teng Yang et al. This is an open access article distributed under the Creative Commons Attribution License, which permits unrestricted use, distribution, and reproduction in any medium, provided the original work is properly cited.

\begin{abstract}
Different from sand and clay, loess has special engineering properties; hence, existing soil grouting theories are not suitable for the disaster treatment of shallow loess tunnels. In this study, a fine grouting reinforcement test system was developed, and the Yuhan Road tunnel overlying loess was used as the injection medium. An orthogonal test based on slurry dry density, moisture content, water-to-cement ratio, and grouting pressure was conducted. Results revealed that the loess samples have high integrity after grouting, and the cohesion and compressive strength improved significantly. The stress-strain curve showed that the strengthened samples have greater ultimate and residual strengths than samples before grouting. Through a range analysis, it was determined that water-to-cement ratio and moisture content are the main factors affecting loess cohesion and compressive strength. Therefore, a comprehensive test of the water-to-cement ratio and moisture content as a single variable was conducted. It was found that their influence on loess cohesion and compressive strength is not a single linear relationship but a combined balance. To characterize the joint effect of water in loess and in slurry on reinforcement, the concept of a comprehensive water-to-cement ratio is proposed, and the cohesion and compressive strength curves with respect to this ratio were drawn. An optimal comprehensive water-to-cement ratio, which corresponds to the maximum cohesion or compressive strength, was found. Based on this ratio, we further propose a method to calculate the water-to-cement ratio of slurry and suitable grouting amount for the Yuhan Road tunnel reinforcement project, in which all solution parameters can be measured via field tests. In the project, a surface layered grouting scheme, based on the optimal comprehensive water-to-cement ratio, was designed. After grouting, loess strength was improved significantly, permeability was reduced greatly, and the overall reinforcement effect was suitable; these results provide a reference for similar projects.
\end{abstract}

\section{Introduction}

In the recent years, many urban underground tunnels have been built, and the possibility of encountering complex geology in engineering construction projects is increasing. Influenced by existing pipelines, buildings, and traffic, urban underground tunnels are often designed as the shallowburied and small clear-distance type [1], which makes their construction highly risky and difficult. These construction challenges become more severe if the tunnels are built in the loess layer. Loess is a type of quaternary sediment with high porosity and joints, and its structure and collapsibility directly affect mechanical properties [2-4]. In the construction of shallow-buried loess tunnels in a complex urban environment, overlying soil settlement can occur easily, resulting in engineering disasters such as surface cracks, collapse, and pipeline rupture.

According to historical disaster case statistics, loess characteristics and shallow-buried conditions play a key role in causing such disasters. Currently, grouting is often used to reinforce the overlying soil of tunnels [5], but it is limited by the lack of research on loess grouting reinforcement theory. Grouting parameters and technology mostly rely on the past experience; hence, a systematic and scientific theoretical guidance is required urgently. 
Presently, research on soil grouting reinforcement mainly focuses on sand and clay [6-8]; little research is conducted on loess. Compared to sand and clay, loess has higher water sensitivity and collapsibility, thus the influence mechanism of the slurry water-to-cement ratio and grouting pressure on its reinforcement is also different from that of clay and sand. For example, if the water-to-cement ratio is too large, water in the slurry will directly weaken the loess and thus affect its reinforcement effects. If the water-tocement ratio is too low, the loess will absorb the water in the slurry and cause the rheological property to deteriorate, which is not conducive to slurry diffusion. Moreover, if the grouting pressure is low, influenced by the water absorption and the micropore structure of loess, the slurry can easily percolate and filtrate [9], thereby affecting the reinforcement effect. If the grouting pressure is high, the loess can rapidly collapse, which has a negative reinforcement impact. Therefore, grouting reinforcement of loess is closely related to water. Under different grouting pressures, water in loess and in the slurry has different effects on reinforcement, which are significantly different from those of grouting in clay and sand.

A few studies have explored the grouting reinforcement mechanism of loess through laboratory tests, but they often use the mixing method to investigate the physical and mechanical properties of modified composites (mixing loess, cement, and other additives) $[10,11]$. However, there are essential differences between the mixing and grouting methods: (1) the cement soil formed by the mixing method is a type of mixed engineering material, and its internal physical and mechanical properties are uniform; (2) the grouting method eliminates the overhead pores in the soil by splitting or compaction, and the loess mechanical properties after reinforcement depend on the soil-slurry interface [12]; (3) as discussed before, grouting pressure plays an important role, but its influence is not considered in the mixing method; (4) grouting vein distribution in the grouting sample is irregular, and shear strength errors measured by direct shear methods are large, while the triaxial shear test is more suitable. In summary, and in general terms, existing laboratory test results are unable to reveal the grouting reinforcement mechanism of loess.

Based on the aforementioned problems, through the development of a fine grouting reinforcement test system, this study attempted to restore the actual grouting environment of loess and prepared reinforcement samples that meet the triaxial shear test requirements. Furthermore, a series of laboratory tests were conducted to study the influence mechanism of water in grouting on loess reinforcement, thereby allowing us to draw a more suitable conclusion for practical engineering.

\section{Grouting Reinforcement Test of Loess Medium}

2.1. Brief Test System Introduction. The fine grouting reinforcement test system for loess is composed of an intelligent grouting control module, a reinforcement module, an auxiliary module, and a pipeline module, as shown in
Figure 1. The test system can achieve the cross design of various grouting and injected medium factors, and the strengthened samples can be tested in the triaxial shear, thereby avoiding the large error caused by the direct shear method.

2.2. Case Study Engineering Background. The Yuhan Road underground tunnel, located in Jinan City, China, was selected as the case study. The underground excavation section is $2335 \mathrm{~m}$ long, with an average buried depth of $7 \mathrm{~m}$. The tunnel is classified as a super shallow-buried type, owning to its 0.36 overburden-to-span ratio. The geological conditions along the tunnel are complex, in which soil and stone are distributed at intervals, and the soil section is mainly loess. After the tunnel entered the loess section from $K 2+450$, small-scale cracks appeared on the surface pavement, as shown in Figure 2(a). When the excavation continued to $K 2+702$, the arch crown had significant settlement and water seepage occurred and gradually evolved into water gushing, with a $10 \mathrm{~m}^{3} \cdot \mathrm{h}^{-1}$ water volume discharge rate, as shown in Figure 2(b). As the strength of the loess overlying the tunnel decreased under water immersion, a ground surface collapse pit appeared shortly, with a length of approximately $100 \mathrm{~m}$ and a width of $8 \mathrm{~m}$. The collapse pit revealed the underground water discharge from the ruptured pipeline, as shown in Figure 2(c).

Owing to the characteristics of the accident, surface grouting was selected as the only method to treat the tunnel overburden; however, there were many difficulties in the design of the grouting parameters for loess. Considering this, an indoor grouting test is regarded as a key method for providing useful suggestions for engineering practices.

2.3. Loess in Tunnel Site. The loess in the tunnel site consists of aeolian-proluvial and alluvial and is mainly nonselfweight collapsible loess, which has a relatively new age sedimentation, brown yellow color, plastic to hard-plastic state, porosity, and vertical joint development. The change law of its physical properties and deformation characteristics is consistent with that of the existing geological zoning for loess engineering but has distinct regional strength characteristics. 80 groups of undisturbed soil in different excavation locations were sampled for physical and mechanical parameter testing, and the sample averaged parameter is presented in Table 1 .

2.4. Orthogonal Test Design. According to previous engineering experience and research results, the dry density of soil $\rho_{d}$, moisture content $w$, slurry water-to-cement ratio $(W: C)$, and grouting pressure $P$ were selected as the orthogonal test basic factors.

The test was a 4 -factor $\times 3$-level orthogonal test, and the orthogonal table L9 (34) was selected. The three dry density levels were designed as $1.4,1.6$, and $1.8 \mathrm{~g} \cdot \mathrm{cm}^{-3}$, and the moisture content levels were $9 \%, 15 \%$, and $21 \%$. As the control index of cement slurry, the water-to-cement ratios were selected as $0.8,1$, and 1.2. Considering surface uplift 


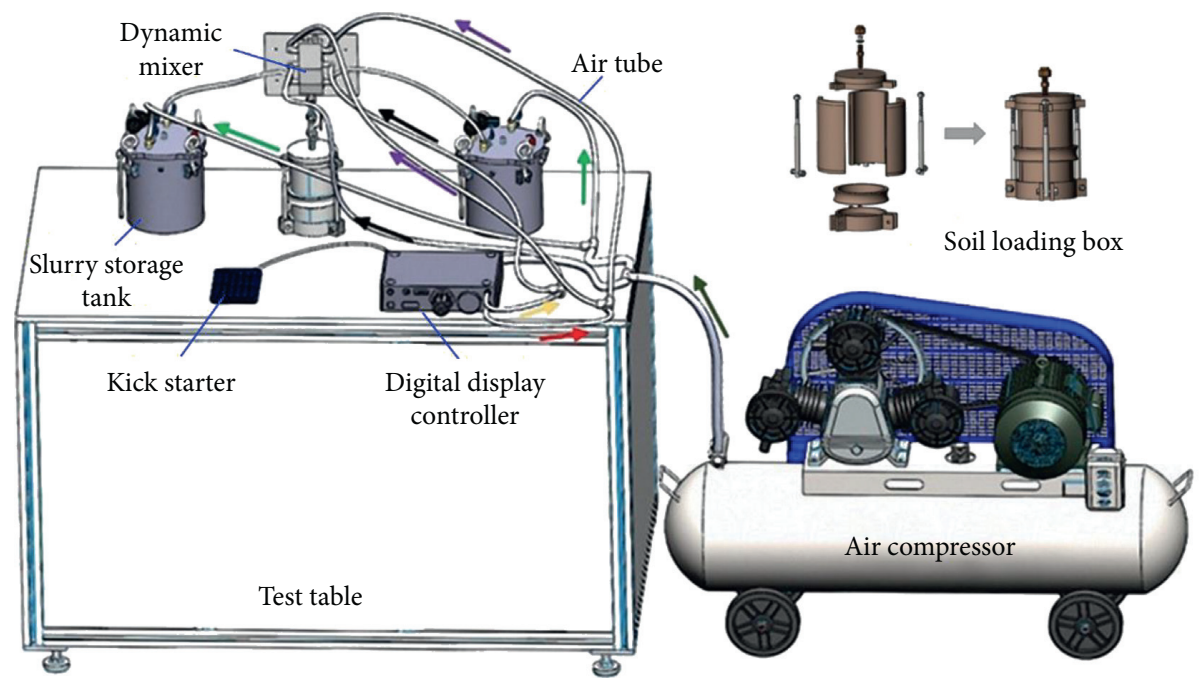

Figure 1: Fine grouting reinforcement test system for loess.

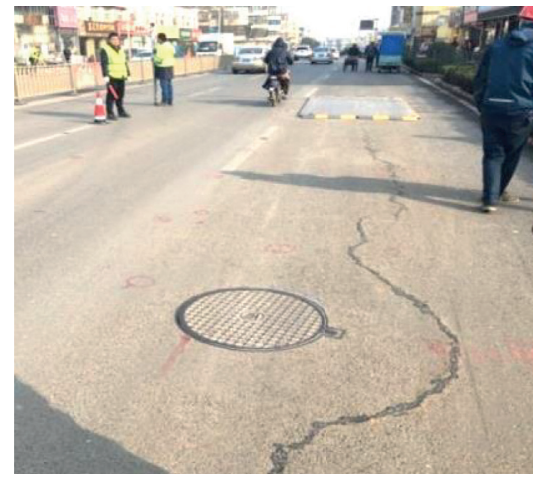

(a)

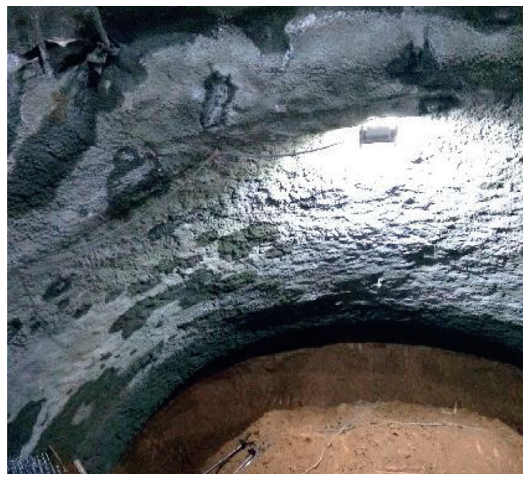

(b)

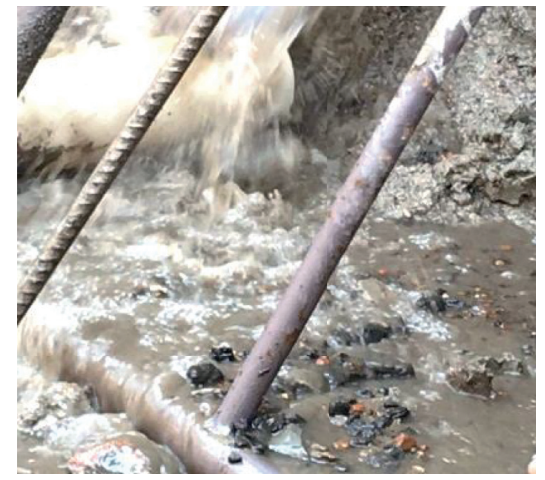

(c)

FIgUre 2: Overburden collapse process for the Yuhan Road urban underground tunnel. (a) Pavement cracks. (b) Partial seepage. (c) Pipeline rupture.

Table 1: Physical and mechanical parameters of loess in the tunnel site.

\begin{tabular}{lccccccc}
\hline $\begin{array}{l}\text { Dry density } \rho_{d} \\
\left(\mathrm{~g} \cdot \mathrm{cm}^{-3}\right)\end{array}$ & $\begin{array}{c}\text { Moisture } \\
\text { content } w(\%)\end{array}$ & $\begin{array}{c}\text { Void } \\
\text { ratio } e\end{array}$ & $\begin{array}{c}\text { Plasticity } \\
\text { index } I_{P}\end{array}$ & $\begin{array}{c}\text { Liquid } \\
\text { index } I_{L}\end{array}$ & $\begin{array}{c}\text { Compressive strength } \\
q_{u}(\mathrm{kPa})\end{array}$ & $\begin{array}{c}\text { Cohesion } \\
c_{c u}(\mathrm{kPa})\end{array}$ & $\begin{array}{c}\text { Internal friction } \\
\text { angle } \varphi_{c u}\left({ }^{\circ}\right)\end{array}$ \\
\hline 1.61 & 18.6 & 0.86 & 14.4 & 0.19 & 182.6 & 47.3 & 25.6 \\
\hline
\end{tabular}

and tunnel deformation, the three grouting pressure levels selected were $1.5,2$, and $2.5 \mathrm{MPa}$. The test arrangement is shown in Table 2.

2.5. Test Procedure. The orthogonal tests were performed according to the following procedure:

(1) A layered filling method was used to fill the remolded soil into the assembled loading box. Each layer was $5 \mathrm{~cm}$ high, and the layered surface was roughened.

(2) The test system was assembled according to the working principle, and the system connectivity and sealing were verified by water injection.
TABLE 2: Orthogonal test arrangement.

\begin{tabular}{lcccc}
\hline Test number & $\begin{array}{c}\text { Factor 1 } \\
\rho_{d}\left(g \cdot \mathrm{cm}^{-3}\right)\end{array}$ & $\begin{array}{c}\text { Factor 2 } \\
P(\mathrm{MPa})\end{array}$ & $\begin{array}{c}\text { Factor 3 } \\
w(\%)\end{array}$ & $\begin{array}{c}\text { Factor 4 } \\
W: C\end{array}$ \\
\hline $\mathrm{T}-1$ & $1(1.4)$ & $1(1.5)$ & $1(9)$ & $1(0.8: 1)$ \\
$\mathrm{T}-2$ & $1(1.4)$ & $2(2.0)$ & $2(15)$ & $2(1.0: 1)$ \\
$\mathrm{T}-3$ & $1(1.4)$ & $3(2.5)$ & $3(21)$ & $3(1.2: 1)$ \\
$\mathrm{T}-4$ & $2(1.6)$ & $1(1.5)$ & $2(15)$ & $3(1.2: 1)$ \\
$\mathrm{T}-5$ & $2(1.6)$ & $2(2.0)$ & $3(21)$ & $1(0.8: 1)$ \\
$\mathrm{T}-6$ & $2(1.6)$ & $3(2.5)$ & $1(9)$ & $2(1.0: 1)$ \\
$\mathrm{T}-7$ & $3(1.8)$ & $1(1.5)$ & $3(21)$ & $2(1.0: 1)$ \\
$\mathrm{T}-8$ & $3(1.8)$ & $2(2.0)$ & $1(9)$ & $3(1.2: 1)$ \\
T-9 & $3(1.8)$ & $3(2.5)$ & $2(15)$ & $1(0.8: 1)$ \\
\hline
\end{tabular}


(3) Fine grouting was conducted to ensure full slurry diffusion in the samples. Considering grouting amount as the test end standard, the grouting amount of each group was taken as $200 \mathrm{ml}$ through preliminary tests.

(4) The reinforcement samples were demolded $5 \mathrm{~h}$ after the test and cured at $20 \pm 2^{\circ} \mathrm{C}$ for 7 days. Subsequently, a consolidated undrained triaxial shear test and an unconfined compression test were conducted.

\section{Test Result Analysis}

3.1. Shear Strength of Reinforced Loess. By analyzing the triaxial shear test stress-strain curves shown in Figure 3, it was determined that the reinforced loess ultimate strength is attained under low strain conditions $\left(\varepsilon_{1}=2.8-4.6 \%\right)$, while the remolded loess corresponding to the axial strain was $\varepsilon_{1}=6.4-9.2 \%$. Additionally, the reinforced loess had large ultimate and residual strengths, which indicates that it has brittle characteristics, strong structural integrity, and that the void structure in the loess has been effectively improved.

Based on the reinforced sample ultimate strength values $\left(\sigma_{1}-\sigma_{3}\right)$, cohesion $c$ and internal friction angle $\varphi$ were calculated and compared with the remolded loess shear strength index before reinforcement and under the same conditions. The variation range is presented in Table 3.

After grouting reinforcement, the ultimate strength of samples $\left(\sigma_{1}-\sigma_{3}\right)$ changed on a wide range of values, with the largest increasing rates resulting from higher confining pressures. Furthermore, the maximum increasing value increased by $222 \%$ (for T-2, $\sigma_{3}=300 \mathrm{kPa}$ ). Cohesion $c$ increased significantly, increasing by a maximum of approximately $866 \%$ and by $241 \%$ on average. The internal friction angle $\varphi$ increased slightly, and the maximum increase was $25 \%$; however, some samples decreased slightly, such as T-6, T-8, and T-9. The reasons are as follows. The tests of samples T-6, T-8, and T-9 had good soil compactness, large grouting pressure, and low soil moisture content; therefore, grouting primarily played a role in compaction. The higher grouting pressure could have easily severed the connections between the soil particles and reduced the friction between particles; thus, the change in the internal friction angle $\varphi$ was negative, and there was a reduction in the increase in cohesion $c$. These test results reveal that the improvement in loess shear strength mainly results in enhanced cohesion $c$, and that there is a general improvement in the internal friction angle $\varphi$.

3.2. Compressive Strength of Reinforced Loess. The stressstrain curves obtained from the unconfined compression tests were all single peak curves, as shown in Figure 4 . The growth rate of most samples before peak stress was smooth, with obvious linear characteristics. Results show that the strengthened samples presented good integrity and homogeneity and certain elastic characteristics. After achieving peak stress, the rate of change increased and stress was significantly reduced, showing obvious plastic characteristics. The samples retained some residual strength after the test ended. These results indicate that the loess samples have certain ductility characteristics after grouting. Compared with the loess samples stress-strain curves before grouting, only a few samples without grouting show plastic characteristics after peak stress, and the stress of the other samples decreases rapidly with increasing strain, showing a more brittle characteristic with relatively low residual strength.

The compressive strength change amplitude of each group of samples before and after reinforcement, i.e., $q_{u}$ and $q_{u-g}$, respectively, was calculated; the results are shown in Table 4. After grouting reinforcement, the compressive strength of loess was improved significantly, with the strength increasing by $368-1620 \%$, and the reinforcement effect was different under different test conditions.

3.3. Analysis of Main Control Factors. The range analysis method was used to determine the influence of loess dry density, moisture content, slurry water-to-cement ratio, and grouting pressure on reinforced loess cohesion and uniaxial compressive strength, as shown in Table 5.

Under these test conditions, the ranges of water-to-cement ratio and moisture content were far greater than those of grouting pressure and loess dry density. Therefore, the slurry water-to-cement ratio and loess moisture content are the main control factors; hence, they are the factors that have the greatest influence on the reinforced sample cohesion and compressive strength. These factors are followed by the grouting pressure and dry density, consecutively.

3.4. Failure Characteristics of Reinforced Loess. Compared with the loess samples before grouting, no local failure was observed in the reinforced samples. The failure mode of these samples was development crack penetration failure, which indicated that the samples have high integrity. The grout vein distribution characteristics are different under different test parameters, and the corresponding reinforcement mode and failure characteristics are also different. Some samples have obvious fracturing slurry veins on the surface, and there is evident stress concentration at the soilslurry interface; thus, the sample crack near the veins, as shown in Figure 5. There is no obvious cement slurry observed on the surface of the other samples; however, cylindrical compacting slurry veins are found in the interior, and the samples crack along the slurry veins to the surrounding area, as shown in Figure 6.

\section{Influence Mechanism of Water-to-Cement Ratio and Moisture Content on Reinforced Loess Strength}

The slurry water-to-cement ratio and the loess moisture content are the main factors affecting the reinforced loess shear and compressive strengths. Both parameters are related to the amount of water, which further verifies the loess water-sensitive characteristics. An orthogonal test can effectively improve test efficiency but cannot specifically help 


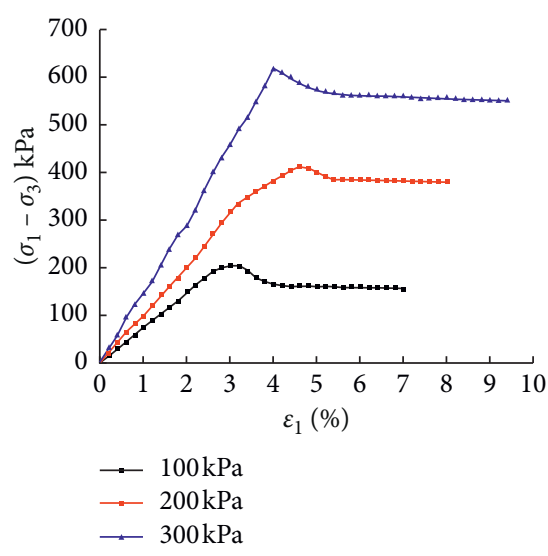

(a)

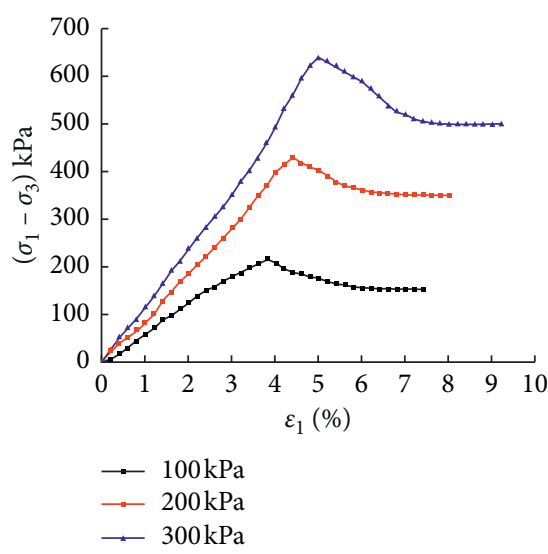

(d)

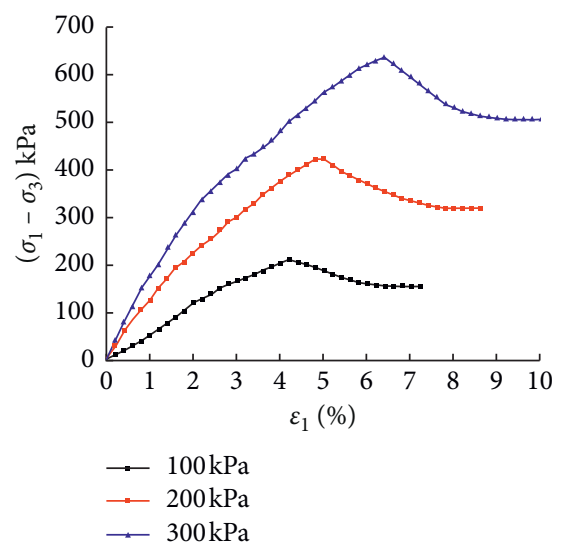

(g)

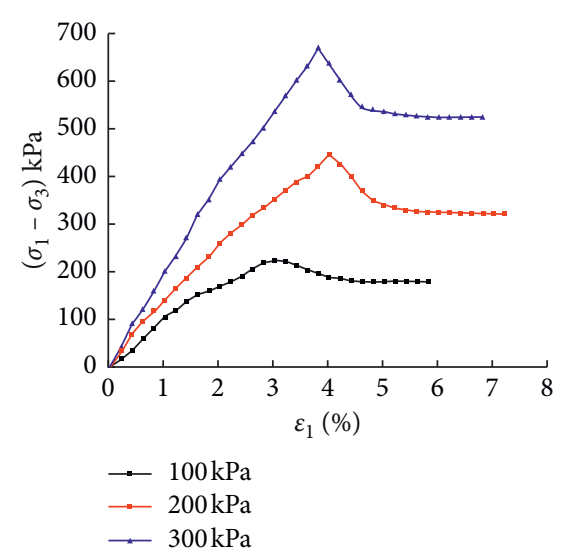

(b)

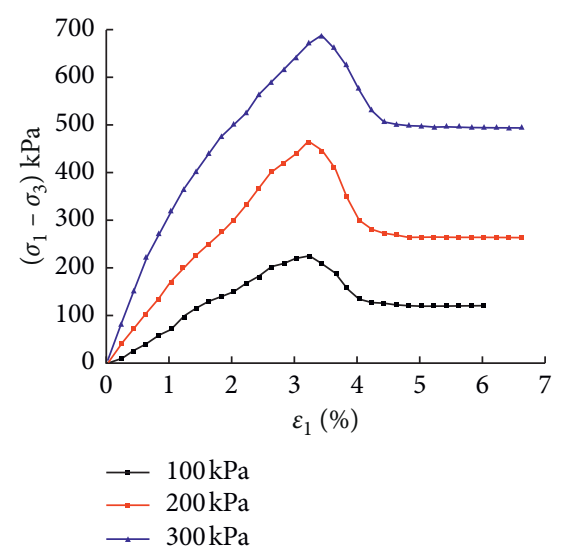

(e)

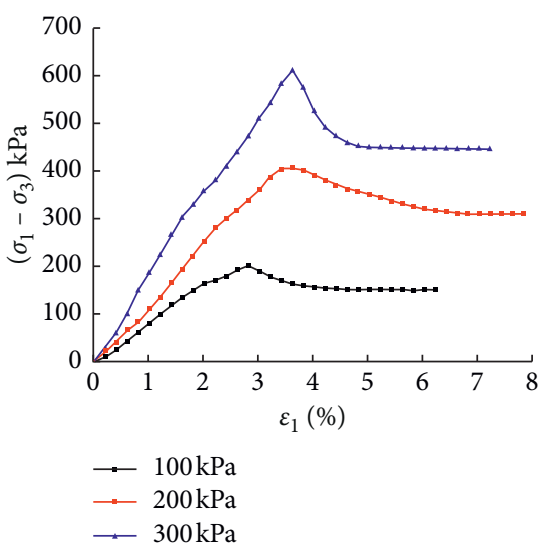

(h)

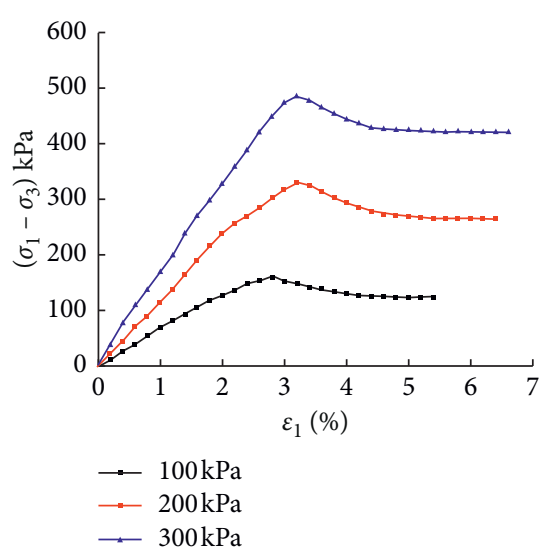

(c)

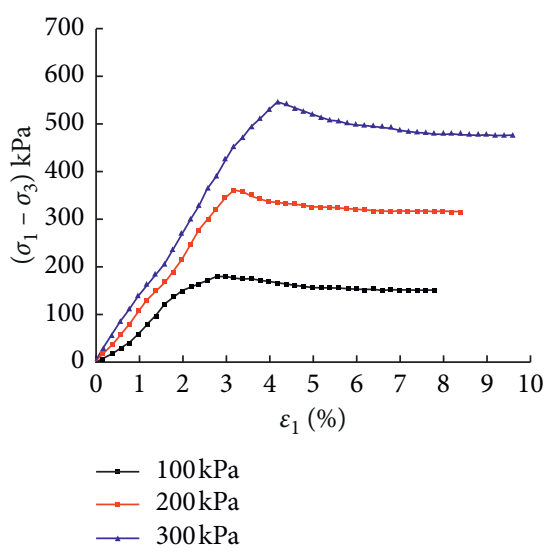

(f)

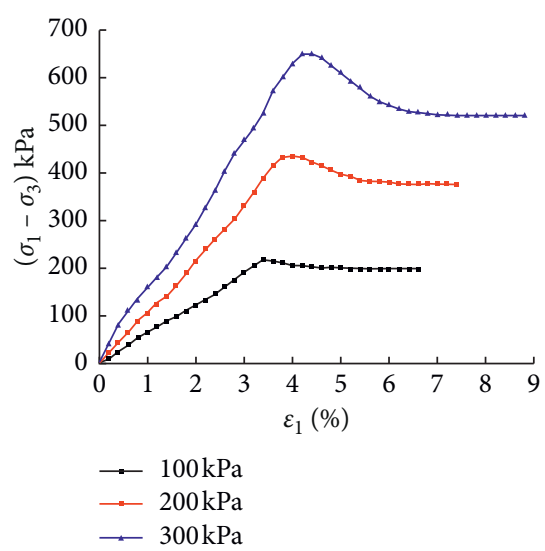

(i)

Figure 3: Triaxial shear test stress-strain curves of reinforced loess. (a) Test-1. (b) Test-2. (c) Test-3. (d) Test-4. (e) Test-5. (f) Test-6. (g) Test7. (h) Test-8. (i) Test-9.

investigate the influence mechanism of either variables separately on the grouting reinforcement effect. Therefore, it is necessary to conduct a comprehensive test of the two variables, focusing on the influence mechanism of water in grouting on loess reinforcement.

4.1. Loess Grouting Test Based on Water-to-Cement Ratio and Moisture Content. The slurry water-to-cement ratios were kept at $0.8,1$, and 1.2 in these orthogonal tests. The loess moisture contents were designed as $9,12,15,18$, and $21 \%$. Additionally, the loess dry density was $1.6 \mathrm{~g} \cdot \mathrm{cm}^{-3}$, grouting pressure was $2.0 \mathrm{MPa}$, and the grouting volume of each sample was $200 \mathrm{ml}$. A comprehensive grouting reinforcement test under 15 working conditions was carried out, as shown in Table 6 . The test procedure was the same as the one used in the previously discussed orthogonal tests. 
TABLE 3: Shear strength index of reinforced loess.

\begin{tabular}{|c|c|c|c|c|c|}
\hline \multirow{2}{*}{ Test number } & \multicolumn{3}{|c|}{$\left(\sigma_{1}-\sigma_{3}\right) \mathrm{kPa}$} & \multirow{2}{*}{$c(\mathrm{kPa})$} & \multirow{2}{*}{$\varphi\left({ }^{\circ}\right)$} \\
\hline & $\sigma_{3}=100 \mathrm{kPa}$ & $\sigma_{3}=200 \mathrm{kPa}$ & $\sigma_{3}=300 \mathrm{kPa}$ & & \\
\hline $\mathrm{T}-1$ & $206(\uparrow 37 \%)$ & $412(\uparrow 127 \%)$ & $618(\uparrow 154 \%)$ & $82.02(\uparrow 36 \%)$ & $30.5(\uparrow 8 \%)$ \\
\hline $\mathrm{T}-2$ & $223(\uparrow 112 \%)$ & $446(\uparrow 214 \%)$ & $668(\uparrow 222 \%)$ & $100.10(\uparrow 378 \%)$ & $31.8(\uparrow 25 \%)$ \\
\hline $\mathrm{T}-3$ & $162(\uparrow 8 \%)$ & $324(\uparrow 62 \%)$ & $486(\uparrow 135 \%)$ & $105.15(\uparrow 866 \%)$ & $26.6(\uparrow 20 \%)$ \\
\hline $\mathrm{T}-4$ & $216(\uparrow 34 \%)$ & $432(\uparrow 129 \%)$ & $649(\uparrow 157 \%)$ & $110.16(\uparrow 222 \%)$ & $31.3(\uparrow 12 \%)$ \\
\hline $\mathrm{T}-5$ & $232(\uparrow 71 \%)$ & $464(\uparrow 176 \%)$ & $697(\uparrow 196 \%)$ & $94.82(\uparrow 352 \%)$ & $32.5(\uparrow 25 \%)$ \\
\hline T-6 & $181(\downarrow 11 \%)$ & $363(\uparrow 58 \%)$ & $544(\uparrow 89 \%)$ & $88.30(\uparrow 28 \%)$ & $28.4(\downarrow 7 \%)$ \\
\hline $\mathrm{T}-7$ & $211(\uparrow 5 \%)$ & $422(\uparrow 59 \%)$ & $633(\uparrow 125 \%)$ & $101.54(\uparrow 166 \%)$ & $30.9(\uparrow 2 \%)$ \\
\hline $\mathrm{T}-8$ & $201(\downarrow 17 \%)$ & $402(\uparrow 22 \%)$ & $604(\uparrow 64 \%)$ & $98.46(\uparrow 33 \%)$ & $30.1(\downarrow 11 \%)$ \\
\hline T-9 & $225(\uparrow 5 \%)$ & $430(\uparrow 54 \%)$ & $645(\uparrow 113 \%)$ & $93.62(\uparrow 90 \%)$ & $31.2(\downarrow 3 \%)$ \\
\hline
\end{tabular}

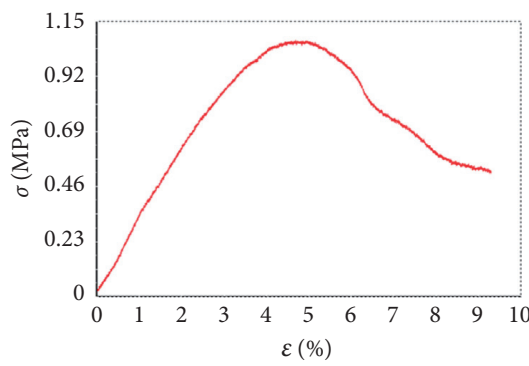

(a)

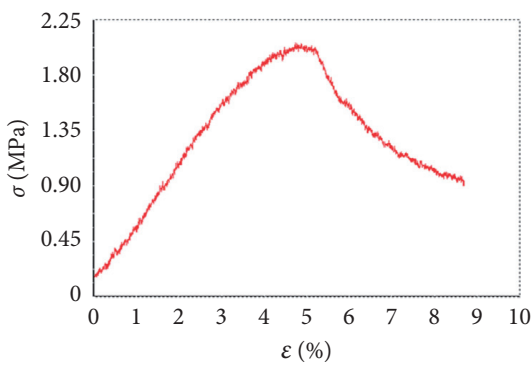

(d)

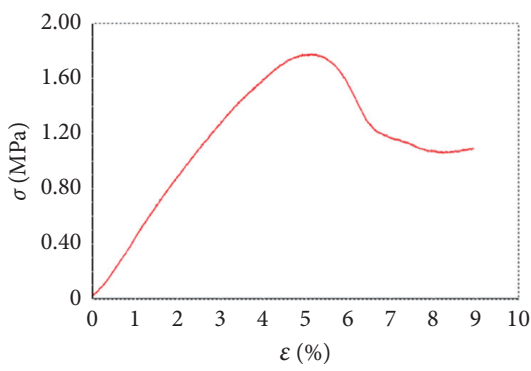

(g)

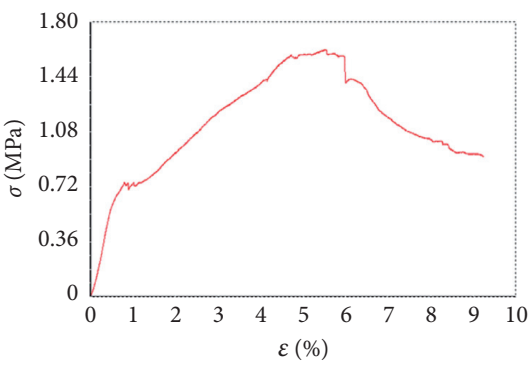

(b)

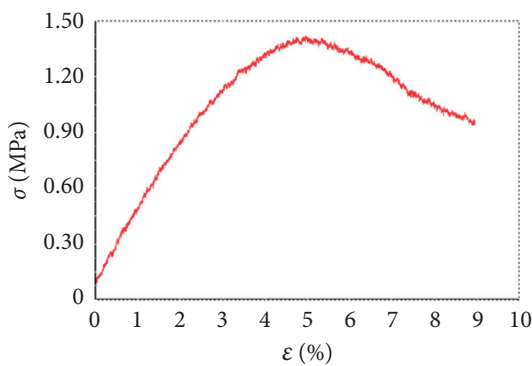

(e)

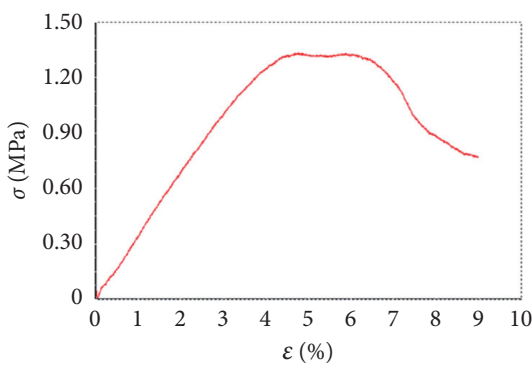

(h)

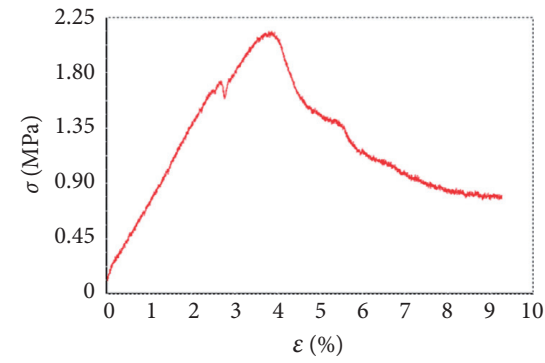

(c)

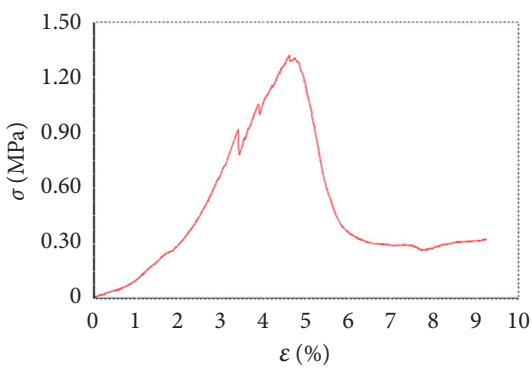

(f)

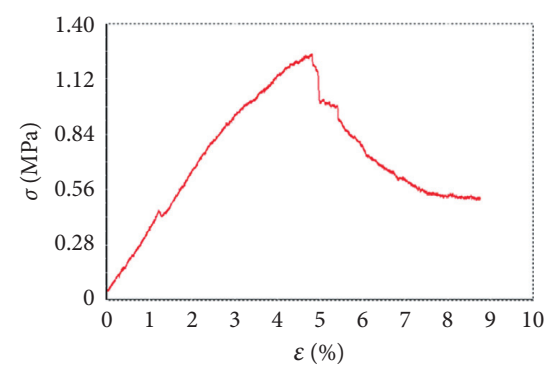

(i)

Figure 4: Unconfined compression test stress-strain curves of reinforced loess. (a) Test-1. (b) Test-2. (c) Test-3. (d) Test-4. (e) Test-5. (f) Test-6. (g) Test-7. (h) Test-8. (i) Test-9.

\subsection{Change of Cohesion and Compressive Strength with} Water. A triaxial shear test and an unconfined compression test were conducted for the reinforced loess; moreover, cohesion $c$ and compressive strength $\sigma_{u}$ were calculated under various working conditions. Their change curves with respect to the water-to-cement ratio $(W: C)$ or moisture content $w$ are shown in Figures 7 and 8 , respectively.
Results show that cohesion and compressive strength increase with an increase in the moisture content under low water-to-cement ratio conditions $(W: C=0.8: 1)$ and decrease with an increase in the moisture content under high water-to-cement ratio conditions $(W: C=1.2: 1)$. For a midlevel water-to-cement ratio ( $W: C=1.0: 1)$, the cohesion and strength first increase and then decrease with an increase in the moisture content. 
TABLE 4: Compressive strength variation amplitude of loess before and after grouting

\begin{tabular}{lccccccccc}
\hline Test number & T-1 & T-2 & T-3 & T-4 & T-5 & T-6 & T-7 & T-8 & T-9 \\
\hline$q_{u-g}(\mathrm{kPa})$ & 980 & 1645 & 2112 & 2308 & 1250 & 1023 & 1862 & 1392 & 1193 \\
$q_{u}(\mathrm{kPa})$ & 182.3 & 152.4 & 122.8 & 175 & 134.6 & 218.6 & 145.3 & 261.2 & 203.3 \\
Percent increase (\%) & 438 & 979 & 1620 & 1219 & 829 & 368 & 1181 & 433 & 487 \\
\hline
\end{tabular}

TABle 5: Range analysis of cohesion (compressive strength) of reinforced loess.

\begin{tabular}{lcccc}
\hline Analysis index & $\rho_{d}\left(g \cdot \mathrm{cm}^{-3}\right)$ & $P(\mathrm{MPa})$ & $w(\%)$ & $W: C$ \\
\hline$K_{1 j}$ & $287.17(4737)$ & $293.72(5150)$ & $268.78(3395)$ & $270.46(3423)$ \\
$K_{2 j}$ & $293.28(4581)$ & $293.28(4287)$ & $303.78(5146)$ & $289.84(4530)$ \\
$K_{3 j}$ & $293.62(4447)$ & $287.07(5150)$ & $301.51(5224)$ & 3 \\
$n$ & 3 & 3 & $89.59(1132)$ & 3 \\
$k_{1 j}$ & $95.72(1579)$ & $97.91(1429)$ & $101.26(1715)$ & $90.15(1141)$ \\
$k_{2 j}$ & $97.76(1527)$ & $95.69(1717)$ & $100.50(1741)$ & $104.59(1937)$ \\
$k_{3 j}$ & $97.87(1482)$ & $2.22(291)$ & $11.67(609)$ & $96.61(1510)$ \\
$D_{j}$ & $2.15(97)$ & & & $14.44(769)$ \\
\hline
\end{tabular}

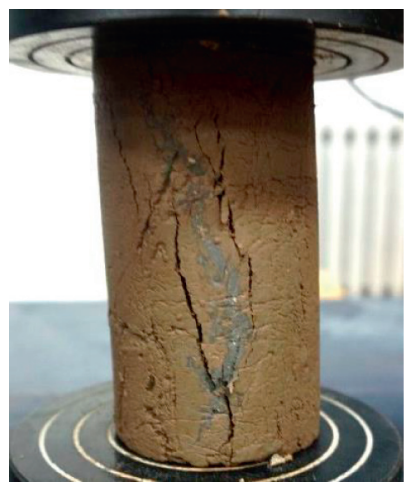

(a)

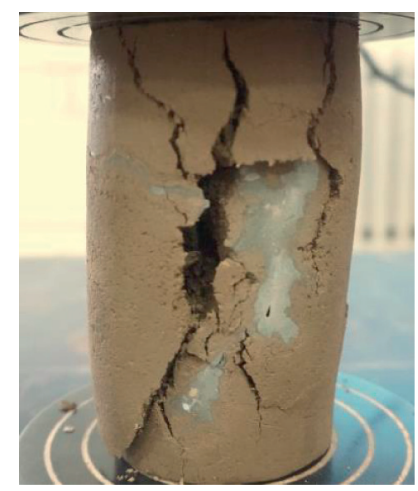

(b)

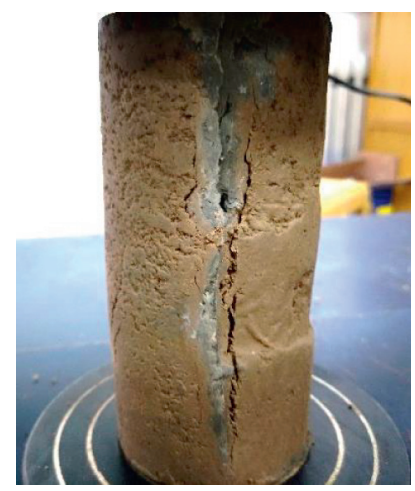

(c)

FIgURE 5: Fracturing slurry veins in the reinforced loess.

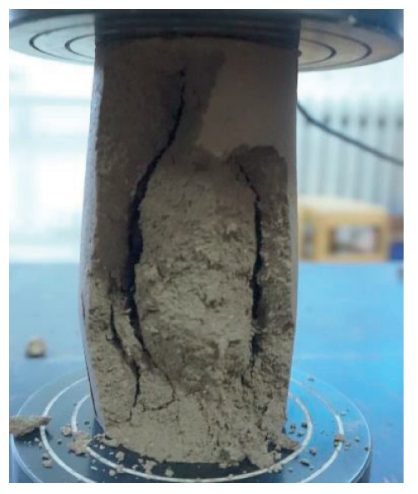

(a)

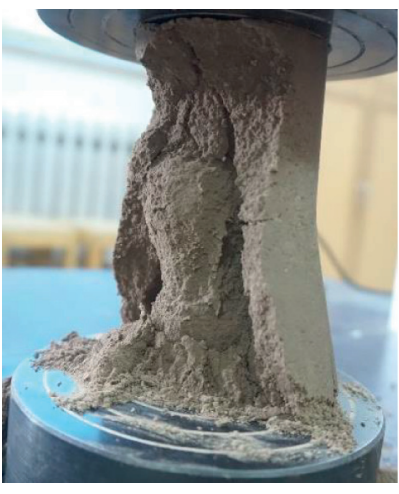

(b)

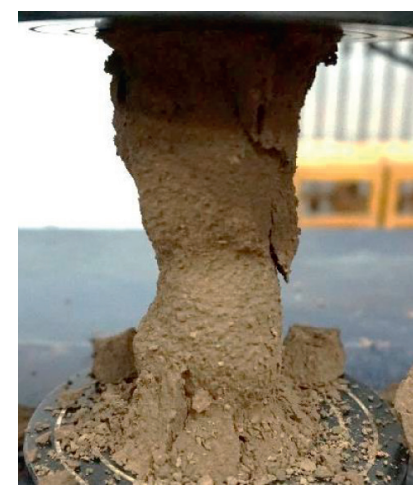

(c)

FIgURE 6: Compacting slurry veins in the reinforced loess.

When the moisture content is low ( $w=9 \%$ and $12 \%$ ), cohesion and compressive strength increase with an increase in the water-to-cement ratio; the lower the moisture content, the more rapid is the growth. When the moisture content is high $(w=18 \%$ and $21 \%)$, the cohesion and compressive strength decrease with an increase in the water-to-cement ratio. The higher the moisture content, the faster is the reduction rate. For midlevel moisture content $(w=15 \%)$, cohesion and compressive strength first increase and then decrease as the water-to-cement ratio increases.

This analysis confirms that the reinforced loess is very sensitive to water. Furthermore, the influence of the slurry 
TABLE 6: Comprehensive test conditions.

\begin{tabular}{lcc}
\hline Test number & $W: C$ & $W(\%)$ \\
\hline II-1 & $0.8: 1$ & 9 \\
II-2 & $0.8: 1$ & 12 \\
II-3 & $0.8: 1$ & 15 \\
II-4 & $0.8: 1$ & 18 \\
II-5* & $0.8: 1$ & 21 \\
II-6 & $1.0: 1$ & 9 \\
II-7 & $1.0: 1$ & 12 \\
II-8 & $1.0: 1$ & 15 \\
II-9 & $1.0: 1$ & 18 \\
II-10 & $1.0: 1$ & 21 \\
II-11 & $1.2: 1$ & 9 \\
II-12 & $1.2: 1$ & 12 \\
II-13 & $1.2: 1$ & 15 \\
II-14 & $1.2: 1$ & 18 \\
II-15 & $1.2: 1$ & 21 \\
\hline
\end{tabular}

water-to-cement ratio and the loess moisture content on cohesion and compressive strength is not a linear relationship but a combined balance.

4.3. Water-Sensitive Effect of Reinforcement. When the slurry enters the soil, it produces hydration products, which cements soil particles and improves soil integrity [13]. Simultaneously, the skeleton formed after slurry solidification also increases soil integrity and strength, as does the slurry veins formed by split grouting and the slurry bubbles formed by compaction grouting [14]. Grouting pressure, grouting volume, and soil dry density are the main factors that determine the grouting mode. In the tests performed for this study, all these factors are quantitative; therefore, the grouting mode and grout diffusion range in the loess samples are not different. Thus, slurry hydration degree in the loess is the main factor affecting the reinforcement effect. When the soil moisture content and the slurry water-to-cement ratio are both low, there will not be enough free water for the hydration reaction, resulting in fewer hydration products and a poor grouting reinforcement effect. In this case, appropriately increasing the slurry water-to-cement ratio is conducive to the full hydration reaction of the slurry, which in turn leads to an improved reinforcement effect. When the soil moisture content and the slurry water-to-cement ratio are both high, the excess water, remaining after the hydration reaction, will weaken soil particle cementation, thus affecting the reinforcement effect. Additionally, excess water will also dilute the hydration product concentration and affect crystallization amounts, making it difficult to form a sufficiently hydrated skeleton. In this case, appropriately reducing the slurry water-to-cement ratio is conducive to avoid residual water in the soil, ensuring a satisfactory reinforcement effect.

\section{Dynamic Grouting Control of Loess Stratum Based on Comprehensive Water-to-Cement Ratio}

5.1. Comprehensive Water-to-Cement Ratio. The loess reinforcement sample strength is affected by water in the slurry and in the soil. To characterize their influence on loess reinforcement quantitatively, the concept of a comprehensive water-to-cement ratio $\left(W_{t} / C_{t}\right)$, based on the studies of Filz et al. [15] and Liu et al. [16] on cement soil strength, is proposed to reflect its common influence on the hydration reaction in grouting. This ratio is defined as

$$
\frac{W_{t}}{C_{t}}=\frac{m_{w-s}+m_{w-g}}{m_{c}},
$$

where $m_{w-s}$ and $m_{w-g}$ represent the water mass in the loess sample and slurry, respectively, and $m_{c}$ is the cement mass in the slurry. Their respective calculations are shown in the following equations:

$$
\begin{aligned}
m_{w-s} & =\frac{w}{1-w} \rho_{d} V, \\
m_{w-g} & =\frac{(W / C)}{\rho_{c}+(W / C)} \rho_{c} Q, \\
m_{c} & =\frac{\rho_{c} Q}{\rho_{c}+(W / C)},
\end{aligned}
$$

where $w$ is the initial soil moisture content; $W / C$ is the slurry water-to-cement ratio; $\rho_{d}$ is the soil dry density, $\rho_{d}=1.6 \mathrm{~g} \cdot \mathrm{cm}^{-3} ; \rho_{c}$ is the cement density, $\rho_{c}=3.1 \mathrm{~g} \cdot \mathrm{cm}^{-3} ; V$ is the medium loading bin volume, $V=374.76 \mathrm{~cm}^{3}$; $Q$ is the sample grouting amount, $Q=200 \mathrm{ml}$.

The comprehensive water-to-cement ratio is obtained by substituting equations (2)-(4) into equation (1):

$$
\frac{W_{t}}{C_{t}}=\frac{w \rho_{d} V}{Q(1-w)}\left(1+\frac{W}{C \rho_{c}}\right)+\frac{W}{C} .
$$

The comprehensive water-to-cement ratio of each working condition is calculated using equation (5), and the respective change rule of cohesion and compressive strength with the comprehensive water-to-cement ratio is described; results are shown in Figure 9. As the comprehensive waterto-cement ratio increases, the loess reinforcement samples cohesion and compressive strength first increase and then decrease. Further, there is an optimal comprehensive waterto-cement ratio, which corresponds to the largest cohesion or compressive strength. The fitting equations (equations (6) and (7)) are obtained using MATLAB to fit the test data; the correlation coefficients are $98.65 \%$ and $97.05 \%$ for cohesion and compressive strength, respectively. Therefore, the more accurate cohesion and compressive strength values are obtained using the fitting equations: 


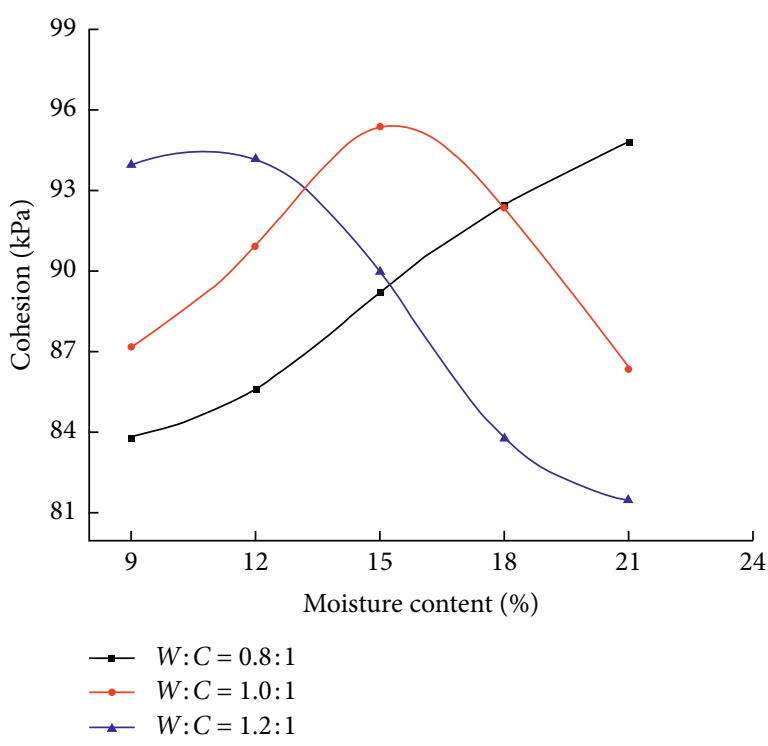

(a)

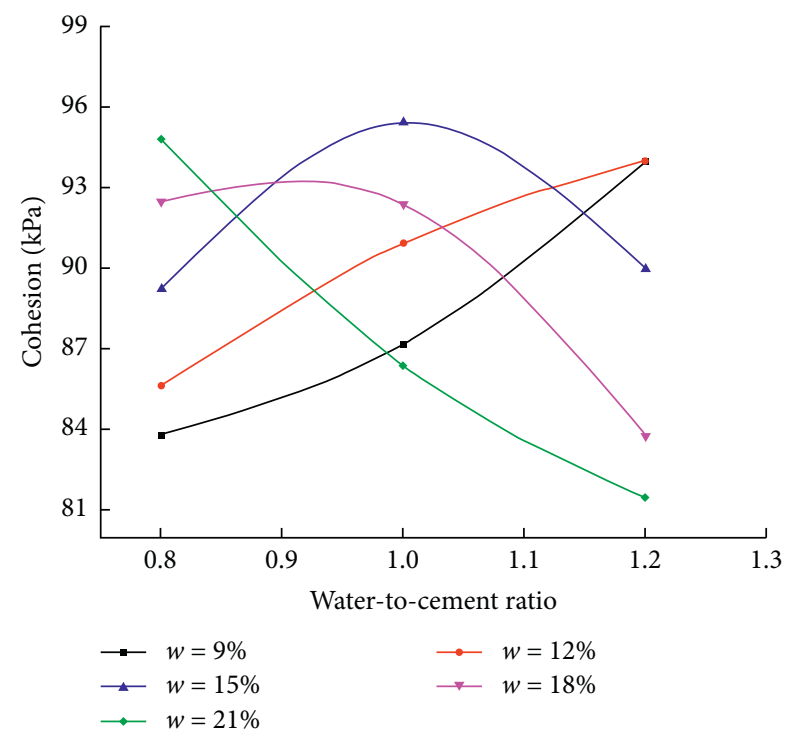

(b)

FIGURE 7: Reinforced loess cohesion vs. moisture content and water-to-cement ratio. (a) $c-w$ curve. (b) $c-W: C$ curve.

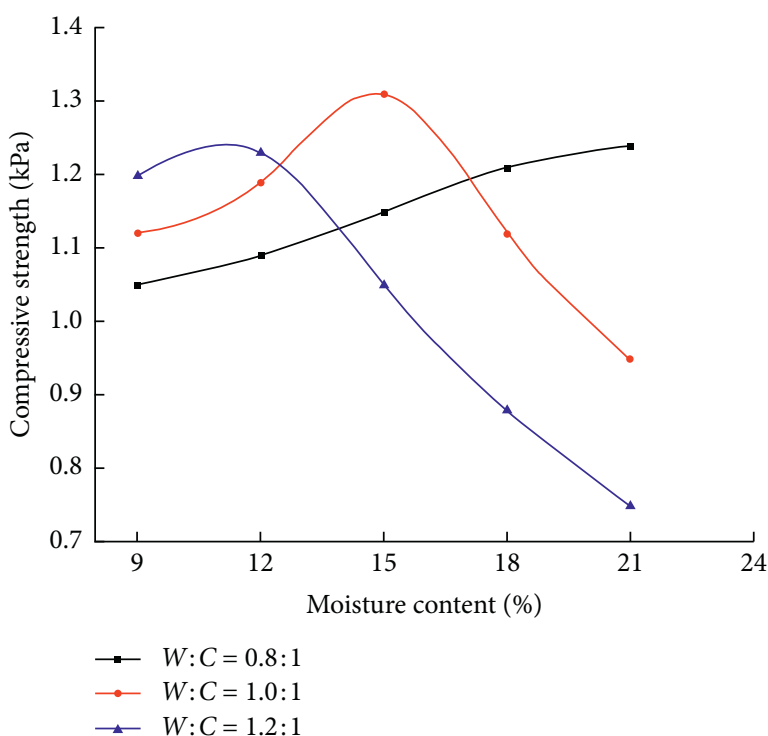

(a)

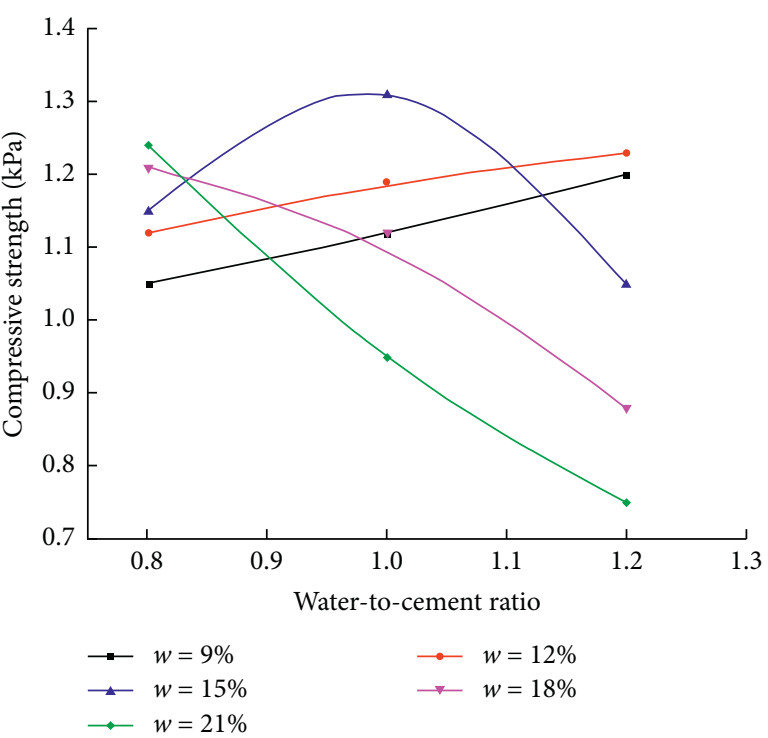

(b)

FiguRE 8: Reinforced loess compressive strength vs. moisture content and water-to-cement ratio. (a) $q_{u}-w$ curve. (b) $q_{u}-W: C$ curve.

$$
\begin{gathered}
c=57.829\left(W_{t}: C_{t}\right)^{4}-422.71\left(W_{t}: C_{t}\right)^{3}+1105.8\left(W_{t}: C_{t}\right)^{2}-1220.6\left(W_{t}: C_{t}\right)+567.07, \\
\sigma_{u}=1.455\left(W_{t}: C_{t}\right)^{4}-10.626\left(W_{t}: C_{t}\right)^{3}+27.71\left(W_{t}: C_{t}\right)^{2}-30.564\left(W_{t}: C_{t}\right)+13.174 .
\end{gathered}
$$

\subsection{Grouting Parameters of Loess Stratum Based on Comprehensive Water-to-Cement Ratio}

5.2.1. Slurry Water-to-Cement Ratio Determination. According to the above results, if the cohesion or compressive strength of reinforced loess is determined, the corresponding comprehensive water-to-cement ratio can be obtained by inverse calculation using equations (6) or (7). Therefore, in the practical grouting of loess stratum, the ideal value of cohesion and compressive strength should be determined first, and then the corresponding comprehensive water-to-cement ratio can be calculated. Through the transformation of equation (5), the slurry water-to-cement ratio could be obtained using equation (8) as follows: 


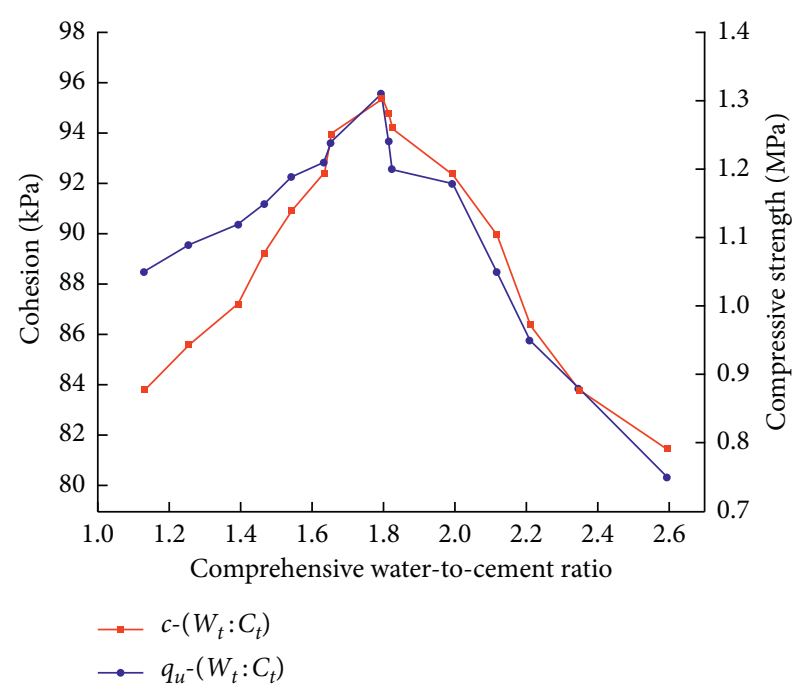

(a)

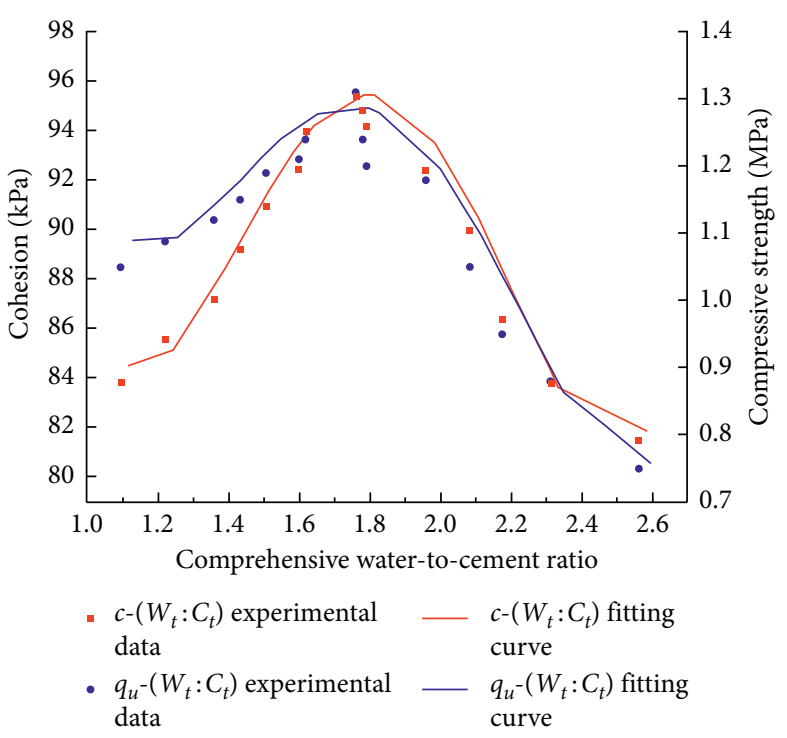

(b)

Figure 9: Measured data and fitting curves of reinforced samples' cohesion and compressive strength with respect to the comprehensive water-to-cement ratio.

$$
\frac{W}{C}=\frac{\rho_{c} Q(1-w)\left(\left(W_{t} / C_{t}\right)-\rho_{c} w \rho_{d} V\right)}{\rho_{c} Q(1-w)+w \rho_{d} V},
$$

where $W_{t} / C_{t}$ is the expected comprehensive water-to-cement ratio; $V$ is the medium loading bin volume, $V=374.76 \mathrm{~cm}^{3} ; Q$ is the sample grouting amount, $Q=200 \mathrm{ml} ; w$ is the initial soil moisture content; $\rho_{d}$ is the soil dry density; $\rho_{c}$ is the cement density. $w, \rho_{d}$, and $\rho_{c}$ can be measured on site.

5.2.2. Grouting Amount Determination. The equation to calculate grouting amount in existing soil reinforcement methods is extremely theoretical, and there are numerous assumptions in the derivation process, such as the slurry diffusion being a laminar flow, the slurry flow pattern as a Newtonian fluid, Bingham fluid, or power-law fluid, and the grouting pressure being linearly attenuated along the diffusion path [17-20]. These assumptions are not practical and do not reflect the corresponding relationship between grouting amount and reinforcement effect; thus, the calculated grouting amount cannot provide effective guidance for actual projects. Based on the comprehensive water-tocement ratio proposed in this manuscript, the grouting amount $Q_{s}$ (unit: cubic soil) can be calculated using the soil moisture content and slurry water-to-cement ratio. Combining equations (1)-(4), a new type of grouting amount, as shown in equation (9), can be obtained; this amount has the advantage that it can be estimated using the expected reinforcement target:

$$
Q_{s}=\frac{\rho_{d} w\left(\rho_{c}+(W / C)\right)}{\rho_{c}(1-w)\left(\left(W_{t} / C_{t}\right)-(W / C)\right)},
$$

where $W / C$ is the slurry water-to-cement ratio determined by equation (8).
5.3. Dynamic Adjustment of Grouting Technology. The constant pressure, or constant rate, method is often used in surface grouting. If the stratum initial moisture content is low, it is necessary to increase the slurry water-to-cement ratio to ensure an optimal comprehensive water-to-cement ratio. However, under constant pressure or constant rate grouting conditions, the slurry may spread excessively along a certain path; thus, intermittent grouting technology is required to ensure a uniform slurry diffusion. Similarly, if the initial stratum moisture content is high, then the slurry water-to-cement ratio needs to be reduced. Under constant pressure or constant rate grouting conditions, the procedure might cause evident stratum disturbance or even surface uplift; thus, it is necessary to adopt low-pressure slow-infiltration technology to ensure the grouting amount. In summary, grouting amount, water-to-cement ratio, and moisture content complement each other to ensure that the comprehensive water-to-cement ratio is optimum. Therefore, in loess stratum grouting projects, it is necessary to adjust the grouting technology dynamically, according to site conditions, to achieve the expected reinforcement effect.

\section{Evaluation of Grouting Engineering Effects}

6.1. Grouting Reinforcement Scheme. To improve soil strength and stability and ensure underground tunnel excavation stability, surface grouting was used to reinforce the loess stratum of the $K 2+677$ to +702 collapse section of the Yuhan Road underground tunnel. A ground-penetrating radar was used to observe the overlying stratum of the tunnel; these observations helped determine that the moisture content of the $0-3 \mathrm{~m}$ stratum was relatively high, owing to underground pipeline leakage, and the moisture content of the 3-7 m stratum was relatively low, as shown in Figure 10 . The average moisture content of the $0-3 \mathrm{~m}$ loess 


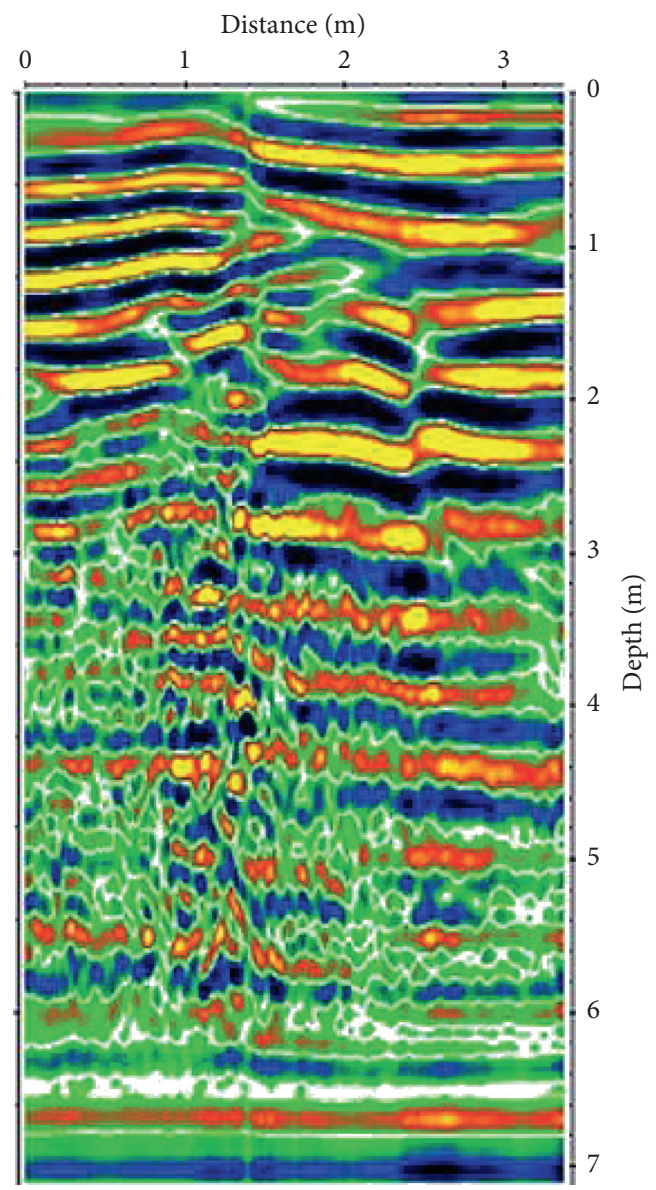

FIgURe 10: Radar data.

stratum was $20.6 \%$ and that of the 3-7 m loess stratum was $14.2 \%$. To prevent the surface uplift caused by slurry upward channeling, a layered grouting reinforcement technology was adopted, i.e., the overlying stratum was divided into the grouting pad (2-3 $\mathrm{m})$ and the reinforcement layer $(3-7 \mathrm{~m})$, as shown in Figure 11.

The long-term stability of the urban underground tunnel is required; thus, the grouting target needs to achieve the best soil reinforcement strength. In this project, the soil maximum cohesion was taken as the target grouting value, which is $94.6 \mathrm{kPa}$ according to equation (6). The corresponding optimal comprehensive water-to-cement ratio is 1.81 , and the corresponding compressive strength, according to equation (7), is $1.24 \mathrm{MPa}$. Therefore, the grouting parameters were designed according to equations (8) and (9), as shown in Table 7.

6.2. Analysis of Grouting Effect. In the surface grouting process, monitoring points were set at the vault of tunnels with different mileage to observe daily settlement. The daily settlement fluctuated under the influence of grouting pressure and grouting amount and tended to be stable on the eighth day after grouting, as shown in Figure 12; the strength of the loess stratum had been greatly improved after grouting. After grouting, the

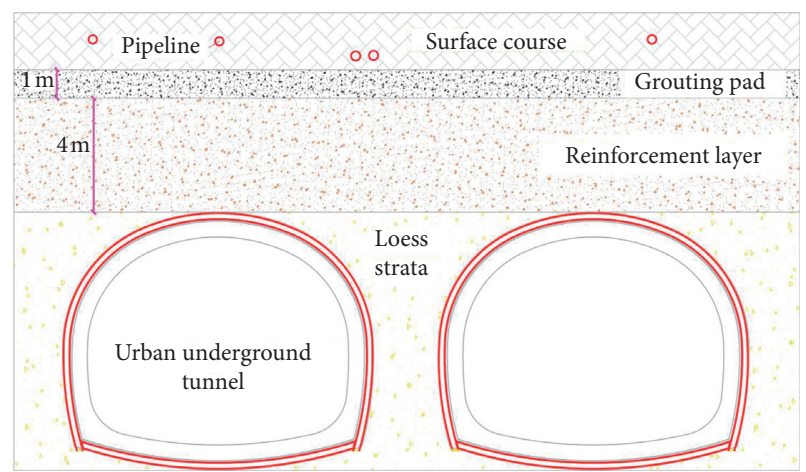

FIGURE 11: Layered grouting reinforcement of overlying loess.

reinforcement effect was verified and evaluated using the inspection hole method. There were no collapsed holes during the inspection, and the hole-forming rate was good, indicating that the reinforced loess stratum was dense and had good overall strength. Several slurry stone bodies were found during drilling and coring in the deep reinforcement layer, as shown in Figure 13. Inspection results demonstrate that the loess stratum was considerably improved, the permeability was significantly reduced, and the regional reinforcement effect was satisfactory. 
TABLE 7: Grouting parameters based on the comprehensive water-to-cement ratio.

\begin{tabular}{lcccccc}
\hline Loess stratum & $\begin{array}{c}\text { Diffusion } \\
\text { radius }(\mathrm{m})\end{array}$ & $\begin{array}{c}\text { Grouting } \\
\text { height }(\mathrm{m})\end{array}$ & $\begin{array}{c}\text { Maximum } \\
\text { pressure }(\mathrm{MPa})\end{array}$ & $\begin{array}{c}\text { Slurry water-to- } \\
\text { cement ratio }\end{array}$ & $\begin{array}{c}\text { Single hole grouting } \\
\text { amount }\left(\mathrm{m}^{3}\right)\end{array}$ & $\begin{array}{c}\text { Grouting method } \\
\text { Grouting pad }(2-3 \mathrm{~m})\end{array}$ \\
$\begin{array}{l}\text { Reinforcement layer } \\
(3-7 \mathrm{~m})\end{array}$ & 1.5 & 1 & 1.5 & 0.8 & 3.74 & $\begin{array}{c}\text { Low pressure slow } \\
\text { infiltration }\end{array}$ \\
\hline
\end{tabular}

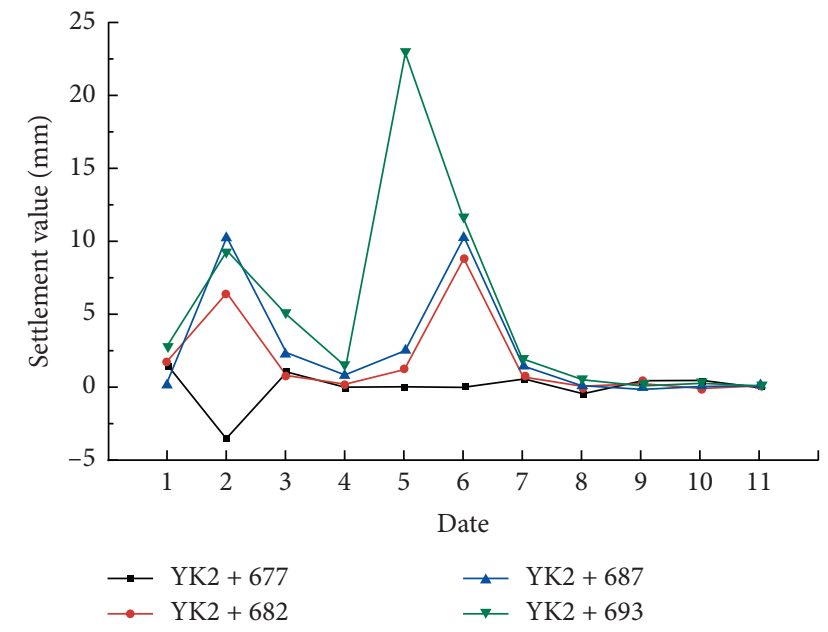

FIGURE 12: Tunnel vault settlement displacement.

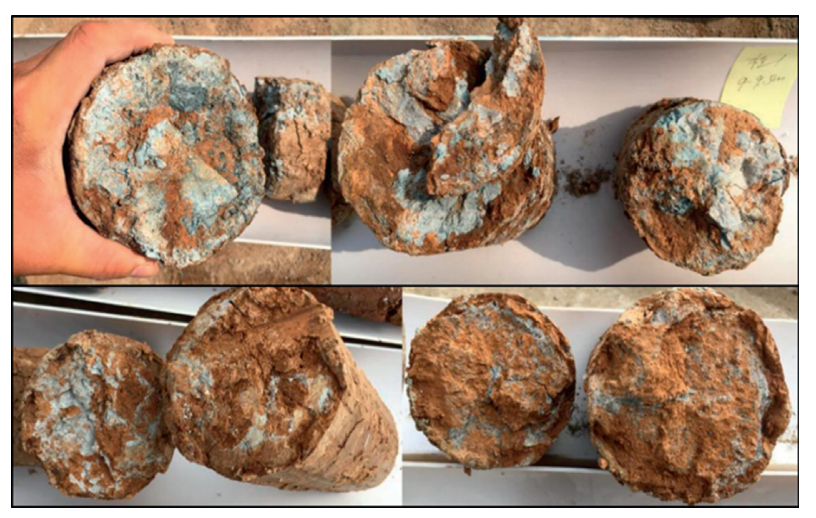

Figure 13: Drilling and coring of reinforced loess.

\section{Suggestions}

The grouting of the overlying loess stratum of urban shallow tunnels is not an easy task due to ground heave, underground pipeline ruptures, and the adjacent building uplift, among other factors. Therefore, it is imperative to study the influence of grouting on soil disturbance and put forward the corresponding control technology. Li et al. [21] analyzed the surface uplift mechanical mechanism caused by grouting and obtained the surface uplift displacement calculation method. On the basis of their research, we can further advance the study of grouting effects in the following two aspects: (1) the influence of grouting depth $h$ on the surface uplift; (2) based on the superposition principle, we can study the influence of porous grouting on the surface uplift, establish the relationship between borehole spacing and uplift displacement, and propose an optimal borehole spacing $d$. The drilling parameters of surface grouting can be obtained from these suggestions, which can make the layered grouting technology proposed in this manuscript more systematic and seamless and reduce the adverse effects of grouting disturbance.

\section{Conclusions}

(1) A new grouting reinforcement test system was developed, which can achieve fine speed and pressure control in the loess grouting process, and is conducive to uniform slurry diffusion in the loess medium. The shear strength and compressive strength of loess reinforcement samples were improved considerably, with a maximum increase of $222 \%$ and $1620 \%$, respectively. Among them, the improvement of shear strength by grouting mainly leads to improvement of the cohesion.

(2) The combined balance of the slurry water-to-cement ratio and the soil moisture content is an important factor, affecting the cohesion and compressive strength of loess reinforcement samples. We put forward the concept of the comprehensive water-tocement ratio to analyze the influence mechanism of water in loess and in slurry on the reinforcement effect. With the comprehensive water-to-cement ratio increase, the loess reinforcement sample cohesion and compressive strength first increased and then decreased, and an optimal comprehensive water-to-cement ratio was determined.

(3) On the basis of comprehensive water-to-cement ratio, the calculation method of the slurry water-tocement ratio and the grouting amount suitable for practical engineering applications was put forward. The parameters used can be measured by field tests. To control the stratum disturbance, a layered grouting control technology was designed and successfully applied in the Yuhan Road underground tunnel in Jinan, China.

Based on these results, this manuscript puts forward three guiding suggestions for the grouting design and application in the overlying loess stratum of an urban shallow tunnel, which can provide a reference for related projects.

\section{Data Availability}

The raw data used to support the findings of this study are available from the corresponding author upon request. 


\section{Disclosure}

Teng Yang and Jiaqi Zhang are the co-first authors.

\section{Conflicts of Interest}

The authors declare that there are no conflicts of interest regarding the publication of this paper.

\section{Acknowledgments}

The research reported in this manuscript was funded by the Natural Science Foundation of Shandong Province (Grant no. ZR2017MEE070).

\section{References}

[1] J. W. Gong, C. C. Xia, and X. W. Lei, "Analysis of filed measurement and theoretical calculation on rock pressure in shallow buried twin tunnels with small spacing," Chinese Journal of Rock Mechanics and Engineering, vol. 29, no. S2, pp. 4139-4145, 2010.

[2] Z. G. Lin and S. J. Wang, "Collapsibility and deformation characteristics of deep-seated loess in China," Engineering Geology, vol. 25, no. 2-4, pp. 271-282, 1988.

[3] T. X. Zhu, "Gully and tunnel erosion in the hilly loess plateau region, China," Geomorphology, vol. 153-154, pp. 144-155, 2012.

[4] J. B. Zhao and C. C. Huang, "Progress of loess research in China," Journal of Geographical Sciences, vol. 14, no. 1, pp. 57-61, 2004.

[5] R. J. Mair and R. N. Taylor, "Theme lecture: bored tunneling in the urban environment," in Proceedings of the 14th International Conference for Soil Mechanics and Foundation Engineering, vol. 4, no. 14, pp. 2353-2385, A A Balkema, Hamburg, Germany, September 1997.

[6] S. C. Nichols and D. J. Goodings, "Physical model testing of compaction grouting in cohesionless soil," Journal of Geothechnical and Geoenvironmental Engineering, vol. 126, no. 9, pp. 848-852, 2000.

[7] A. Bezuijen, "Compensation grouting in sand-experiments, field experiences and mechanisms," Doctoral thesis, Delft University of Technology (TU Delft), Delft, Netherlands, 2010.

[8] Z.-M. Zhang, J. Zou, J.-Y. He et al., "Laboratory tests on compaction grouting and fracture grouting of clay," Chinese Journal of Geotechnical Engineering, vol. 31, no. 12, pp. 1818-1824, 2009.

[9] A. Draganovic, "Bleeding and filtration of cement-based grout," Doctoral thesis, Royal Institute of Technology, Stockholm, Sweden, 2009.

[10] R. Wen and Y. L. Liu, "Study on shear strength characteristics of cement loess," Ningxia Engineering Technology, vol. 5, no. 2, pp. 126-129, 2006.

[11] J. Fang, Q. G. Liang, P. He et al., "Comparative test of tensile and compressive strength of Lanzhou cement improved loess," Railway Engineering, vol. 58, no. 10, pp. 81-85, 2018.

[12] Q. S. Zhang, P. Li, X. Zhang et al., "Model test of grouting strengthening mechanism for fault gouge of tunnel," Chinese Journal of Rock Mechanics and Engineering, vol. 34, no. 5, pp. 924-934, 2015.

[13] B. Bohloli, O. Skjolsvold, H. Justnes et al., "Cements for tunnel grouting-rheology and flow properties tested at different temperatures," Tunnelling and Underground Space Technology, vol. 91, Article ID 103011, 2019.

[14] S. Li, R. Liu, Q. Zhang, and X. Zhang, "Protection against water or mud inrush in tunnels by grouting: a review," Journal of Rock Mechanics and Geotechnical Engineering, vol. 8, no. 5, pp. 753-766, 2016.

[15] G. M. Filz, D. K. Hodges, D. E. Weatherby, and W. A. Marr, "Standardized definitions and laboratory procedures for soilcement specimens applicable to the wet method of deep mixing," in Proceedings of American Society of Civil Engineers, Geo-Frontiers Congress, January 2005.

[16] J. Q. Liu, W. Z. Chen, and J. Q. Yuan, "Test on anti-scouring property of grouting reinforced body in completely weathered granite," Chinese Journal of Rock Mechanics and Engineering, vol. 35, no. 9, pp. 1767-1775, 2016.

[17] V. H. Nguyen, S. Rémond, J. L. Gallias, J. P. Bigas, and P. Muller, "Flow of Herschel-Bulkley fluids through the marsh cone," Journal of Non-Newtonian Fluid Mechanics, vol. 139, no. 1-2, pp. 128-134, 2006.

[18] F. J. Rubio-Hemandez, J. F. Velazquez-Navarro, and L. M. Ordonez-Belloc, "Rheology of concrete: a study case based upon the use of the concrete equivalent mortar," Materials and Structures, vol. 46, no. 4, pp. 587-605, 2013.

[19] R. J. Flatt and P. Bowen, "Yodel: a yield stress model for suspensions," Journal of the American Ceramic Society, vol. 89, no. 4, pp. 1244-1256, 2006.

[20] L.-Z. Zhang, Q. S. Zhang, R.-T. Liu et al., "Grouting mechanism in fractured rock considering slurry-rock stress coupling effects," Chinese Journal of Geotechnical Engineering, vol. 40, no. 11, pp. 2003-2011, 2018.

[21] M. T. Li, X. Zhang, S. C. Li et al., "Grouting lifting numerical methods based on numerical simulation and model experiment," Journal of Harbin Institute of Technology, vol. 51, no. 8, pp. 159-166, 2019. 